\title{
ENSINO E PESQUISA E NADA MAIS? \\ UMA ANÁLISE COM BASE EM CURRÍCULOS LATTES DE PÓS-DOUTORES EGRESSOS DA CAPES
}

\author{
RESEARCH, EDUCATION AND NOTHING ELSE? \\ AN ANALYSIS BASED ON THE CURRICULA OF \\ POSTDOC CAPES GRADUATES ON THE LATTES PLATFORM
}
Recebido em: 04/09/2015• Aprovado em: 17/11/2015 Avaliado pelo sistema double blind review Editora Científica: Cláudia de Salles Stadtlober DOI: 10.13058/raep.2016.v17n1.355

\author{
PEDRO MARCOS ROMA DE CASTRO pedro.castro@capes.gov.br \\ COORDENAÇÃO DE APERFEIÇOAMENTO DE PESSOAL DE NÍVEL SUPERIOR \\ GECIANE SILVEIRA PORTO \\ UNIVERSIDADE DE SÃO PAULO - CAMPUS RIBEIRÃO PRETO
}

\begin{abstract}
RESUMO
No tripé ensino-pesquisa-extensão no processo de pós-doutorado com vista à capacitação docente, a literatura aponta um quadro de impacto razoavelmente positivo sobre as atividades de pesquisa mensuradas pela produção bibliográfica, sobretudo sobre a publicação de artigos em periódicos. No entanto as atuais atividades docentes não se restringem a produção de papers, ficando a pergunta será que a influência do estágio pós-doutoral não é mais abrangente tendo uma influência sobre atividades mais amplas da pós-graduação? Na busca de almejar uma possível resposta para essa questão emblemática, o estudo trabalhou em uma amostra de 978 pesquisadores que possuíam estágio pós-doutoral realizado no exterior, analisando egressos do programa na Coordenação de Aperfeiçoamento de Pessoal de Nível Superior - Capes, verificando a sua produção técnica e de extensão universitária em um cenário ex ante e ex post ao contexto pós-doutoral. Sob a ótica da produção de uma forma mais ampla, os dados apontam para um cenário drástico de impacto nulo para praticamente ${ }_{\mathrm{I}} \%$ da amostra, além disso, registra um impacto leve ou baixo de uma forma geral, mas os dados apontam para exceções que merecem ser consideradas, na busca de se fomentar um cenário mais amplo que vá além das atividades de pesquisa e que considerem o sistema de pós-graduação de uma forma mais sistêmica e integrada a tríade ensino-pesquisa-extensão. Palavras-Chaves: Estágio Pós-doutoral; Capacitação Docente; Ensino; Pesquisa e Extensão Universitária.
\end{abstract}

\begin{abstract}
Within the three prongs of teaching-research-extension in the postdoctoral process leading to professor training, the literature indicates a moderate positive impact on research activities measured by bibliographic production, especially in the publication of articles in journals. However, current teaching activities are not restricted to the production of papers, leaving the question: could the influence of postdoctoral research be broader in scope, having an influence on ampler postdoctoral activities? In seeking a possible answer to this emblematic question, the study worked on a sample of 978 researchers with postdoctoral research abroad and coming from the CAPES (Coordination for the Improvement of Higher Education Personnel) program, verifying their technical and university extension production in a scenario ex ante and ex post to the postdoctoral context. From a broad overview of production, the findings point to a drastic scenario of null impact for almost $11 \%$ of the sample, moreover, they showed a mild or low impact in general. However, the data does indicate exceptions that deserve to be considered in seeking to support a broader scenario that goes beyond research activities and considers the postgraduate system more systematically and integrated with the teaching-research-extension triad. Keywords: postdoctoral research; professor training; education; research and university extension.
\end{abstract}




\section{INTRODUÇÃO}

O estudo é parte de um estudo maior (CASTRO, 20I3) que busca identificar a influência e o impacto da realização do estágio pós-doutoral sobre as atividades da pós-graduação. Esse recorte versa sobre o impacto do pós-doutorado (nas modalidades de pesquisa pós-doutoral para recém-doutores e também estágio sênior) sobre as atividades técnicas e de extensão universitária.

A visão nesse artigo é que a capacitação via estágio pós-doutoral age enquanto peça recente na engrenagem universitária, especialmente no subsistema da pós-graduação, sendo um componente opcional para a carreira acadêmica, mas que, no entanto ganha grande destaque nos últimos anos, dentre outros aspectos, dado a sua relevância para o conhecimento, o aprimoramento de competências, a reciclagem profissional e de forma geral a necessidade de atualização. Ideia esta presente e fortemente alicerçada em dados empíricos, em trabalho constante em Castro, Porto e Kannebley Jr., (2013) e também corroborada pelo levantamento de Calvosa, Repossi e Castro (20II).

Pesquisando-se em sites de revistas nacionais e também nas bases de dados do: Web of Science, Pro Quest, Scielo e portal periódicos da CAPES, buscouse a literatura científica publicada em periódicos utilizando as palavraschaves: postdoctoral research, sabbatical stay, postdoctoral stage, post doctorate, postdoctoral training, capacitación postdoctorales, etapa de post-doctorado, postdoctorado, pós-doutorado, estágio pós-doutoral e treinamento pós-doutoral. E, surpreende a tamanha escassez de trabalhos sobre um assunto, em princípio, tão relevante, seja para a academia, para a gestão e fomento, para os aspectos da carreira docente, da capacitação e formação do pesquisador e para as políticas públicas de maneira mais ampla.

Todos os estudos encontrados são nacionais, não foram encontrados estudos elaborados no exterior e todos tiveram a linha de investigação na direção de uma aferição dos outputs do pós-doutorado. Neste campo investigativo a revisão encontrou apenas cinco artigos (CASTRO; PORTO, 2008, 2OIO, 20I2; CALVOSA; REPOSSI; CASTRO, 20II; CASTRO; PORTO; KANNEBLEY JR., 2OI3) o que mostra que a literatura científica expressa em mídia prestigiosa ainda é escassa e por ser tão recente, também mostra, ser um campo de exploração 
em pesquisa, ainda raro, em fase exploratória e com imenso potencial de desenvolvimento.

O artigo de Castro e Porto (2008), publicado na revista Organizações e Sociedade, parece ser pioneiro, abrindo com êxito um campo de pesquisa até então não explorado. Castro e Porto (20I0) e Calvosa, Repossi e Castro (20II) acabam seguindo a mesma linha deste primeiro paper possuindo em seus trabalhos um mesmo "fio condutor" no que diz respeito às investigações empíricas; pois, utilizam o mesmo método - o da aferição do antes e depois do pós-doutorado e analisam o fenômeno pós-doutoral à luz do referencial teórico da Gestão do Conhecimento.

Castro, Porto e Kannebley (2013) é o único que foge um pouco dessa linha de verificação ex ante e ex post, para a verificação por meio de grupos de controle e análise quasi-experimental. De comum, em todos os cinco artigos há a mensuração com a atribuição de pesos e ponderações para os diversos tipos de produção bibliográfica e sobressai-se que há o balanço de que a atual conjuntura impulsiona a valorização da capacitação docente, o que configura relevância à análise do valor final da qualificação promovida, estabelecendo motivação para a pesquisa e busca de aferição dos seus resultados.

Todavia, tem-se que ressaltar que a Pós-Graduação enquanto parte integrante do sistema universitário, também tem como sustentáculo o tripé Ensino-Pesquisa-Extensão, mas surgiu uma lacuna vez que todos os artigos trabalharam com a aferição exclusiva da produção em Pesquisa e não havia nenhum indicador construído para a aferição nas demais outras atividades da pós-graduação. Diante disso, se fez necessário criar indicadores próprios, como será descrito minuciosamente na seção de método.

Dessa maneira como objetivo geral o estudo procurou desenvolver indicadores de análise que dimensionassem a influência do sistema de capacitação em nível de pós-doutoramento para o desempenho docente no que diz respeito as atividades próprias do sistema de pós-graduação nacional e mais especificamente, das atividades que vão além da Pesquisa e do Ensino, envolvendo as atividades técnicas, produções tecnológicas e de uma forma mais ampla, a prestação de serviços por meio da extensão universitária. 


\section{O PÓS-DOUTORADO E A EXTENSÃO}

A universidade enquanto instituição tem suas origens na história no início da modernidade, nessa época, a ciência, entendida como o saber nascido do exame sistemático e cuidadoso de fenômenos, passou a ser vista como motor do desenvolvimento e símbolo do progresso. Desde então, estabeleceu-se uma forte associação entre ciência e desenvolvimento econômico-social, fazendo surgir organizações universitárias com o propósito de produzir ciência e revertê-la em resultados práticos para a humanidade (GOERGEN, 1998).

Desde a sua gênese, dimensões foram se constituindo ao longo da história das universidades modernas com o propósito de produzir conhecimento, formar pessoas e transformar saber e atividades de desenvolvimento econômico e social. Considerando esse propósito, Moraes (1998) considera a existência de três identidades que coexistem na organização universitária:

- a universidade como lugar privilegiado de preparação para o exercício de profissões, cada vez mais regulamentadas e credenciadas; [ensino] - a universidade como lugar de pesquisa, do ensino da pesquisa e da busca de novos conhecimentos; e, [pesquisa]

- a universidade como agente prestador de serviços a comunidade. [extensão]

Em sintonia com essas identidades, do ponto de vista legal e normativo, no Brasil, de acordo com a LDB/96, Lei de Diretrizes e Bases, define-se universidades como "Instituições pluridisciplinares de formação dos quadros profissionais de nível superior, de pesquisa, de extensão e de domínio e cultivo do saber humano" (LEI 9.394/96, Art. 52).

Goergen (1998) aborda que ao longo dos tempos, as mudanças econômicas e sociais imprimiram mudanças na relação existente entre universidade, ciência e sociedade. Hoje se espera, que cada vez mais, realize serviços, produza conhecimentos e também forme pessoas capazes de atender aos quesitos de um mundo moldado pela ciência e tecnologia; com consequências para a estrutura administrativa, organizações curriculares, procedimentos acadêmicos e para a própria função da universidade. 
No momento atual, conhecimento virou sinônimo de vantagem competitiva, qualidade de vida e possibilidade de inserção no mundo globalizado. Países "avançados”, com alto grau de desenvolvimento em C\&T (Ciência e Tecnologia), que concentram a capacidade de inovar, detendo a propriedade do conhecimento, fazem com que a relação do mundo globalizado seja assimétrica e exija, assim, novos arranjos das universidades brasileiras. Elas devem ser capazes de atender às exigências por novos conhecimentos e tecnologias economicamente viáveis e socialmente necessárias, unindo o universal-global ao particular-nacional (KAWASAKI, I997).

APós-Graduaçãoenquanto parteintegrantedo sistema universitário, também tem como sustentáculo o tripé Ensino-Pesquisa-Extensão, o surgimento dos estudos em nível de Pós-Graduação, no mundo contemporâneo, adveio com o acúmulo de conhecimentos nos diversos ramos da ciência e à crescente especialização das técnicas. O desenvolvimento da ciência e tecnologia aconselharia introduzir na educação superior uma hierarquização de níveis de estudo: graduação, cujo objetivo seria a instrução científica, humanista, "da massa crítica” e formação profissional, e a pós-graduação, cujo objetivo seria criar uma superestrutura destinada à pesquisa e o desenvolvimento da Ciência, Tecnologia e da Cultura (MEC, parecer 977, 1965).

Visões mais recentes enxergam o processo de extensão universitária inserido no contexto da educação superior como um caminho em direção à execução de sua função social, promovendo a integração com a comunidade externa e elevação do nível cultural do entorno a partir da participação da universidade como agente ativa do desenvolvimento (FERNANDES et al., 20I2; HERNÁNDEZ, 2OI3; CAMARGO; MIGUEL; ZANATA, 20I5).

No Brasil, em i965, com o Parecer 977 do Conselho Federal de Educação, dá-se a implantação formal dos cursos de pós-graduação. Este parecer tendo como relator o conselheiro Newton Sucupira, distinguiu os cursos de PósGraduação em duas categoriais: lato sensu e stricto sensu. Os cursos lato sensu referem-se a cursos de especialização, cujos objetivos são de caráter técnico-profissional e os stricto sensu referem-se a cursos, de mestrado e doutorado, que são orientados para o caráter científico e tecnológico, a natureza acadêmica e a pesquisa. 
Pela visão dos egressos do sistema de pós-graduação na área de administração, há um entendimento de que os órgãos governamentais (MEC e CAPES) valorizam mais a formação do pesquisador em detrimento da formação docente, dados os critérios adotados para a avaliação dos programas de pós-graduação (SOUZA-SILVA; DAVEL, 2005), e considera-se que não se trata apenas da dicotomia foco na pesquisa versus foco na docência, dados pelos próprios docentes na sua atuação nas Instituições de Ensino Superior, mas pode ser um reflexo dinâmico de um contexto mais amplo de fomento, que também se encontra impregnado por essa dicotomia (VALADÃo JR.; RODRIGUES, 20I2).

Nesse contexto de formação para a pesquisa; vale frisar, que a pósgraduação stricto sensu no Brasil, não se limita à elaboração de uma dissertação ou tese, compreende uma série de disciplinas que coloca o aluno a cobrir ampla extensão de um campo do conhecimento, trata-se de uma experiência intensiva de aprendizagem, que envolve a pós-graduação stricto sensu na formação de recursos humanos altamente especializados.

O Pós-doutorado surge no cenário da pós-graduação na década de 90, como um item "extra" na carreira acadêmica, que considerando o escalonamento existente, tem seu ponto máximo de exigência o título de doutorado. A ideia inicial foi potencializar o uso dos recursos humanos e financeiros envoltos diretamente com o cenário da produção e disseminação da ciência e tecnologia, com vistas a ampliar a participação dos pesquisadores brasileiros no mainstream da ciência e facilitar a inserção na comunidade científica internacional.

Conforme levantando por Coraiola et al. (2013), os professores universitários da área de Administração, que realizam pós-doutorado possuem um perfil não voltado para atividades da empresa ou para o setor produtivo, os docentes que realizaram pós-doutorado possuem um perfil que volta-se, sobretudo para as atividades acadêmicas, do ensino e sobretudo da pesquisa. Esse mesmo caráter é visto na literatura em outros países (RECOTILLET, 2007). No entanto, para Coraiola et al (2013) o pós-doutorado não deveria ser relevante somente para o aumento da produção científica, mas também para a melhoria de outras atividades docentes. 
À luz da gestão do conhecimento (NONAKA; TAKEUCHI, I997), da gestão do conhecimento científico (LEITE; COSTA, 2007; LEYDESDORFF 2007) e sob a perspectiva da produção científica, Castro e Porto (2008), abordam o pós-doutorado situando-se em uma região híbrida que abre espaço para uma situação onde se mescla e se alterna condições de desenvolvimento e de aquisição de conhecimentos via práticas de outros laboratórios de pesquisa e conectividade com outras práxis acadêmicas, caracterizando um processo de interação e de socialização entre os pesquisadores em que se estabelecem situações de aprendizagem por meio de conhecimentos que são eminentemente tácitos, entretanto espera-se que o processo depois possa convergir para novas produções científicas e tecnológicas.

Apesar de ser atualmente motivo de desejo de muitos doutores, por desenhar-se como um caminho atrativo e promissor, os dados da literatura mostram que atuar em parceira com o objetivo centrado unicamente na busca do incremento na produção bibliográfica e aumento dos "escores e linhas adicionais no Lattes" parece não ser uma estratégia liquida e certa. Castro, Porto e Kannebley (2013), por exemplo com o uso de grupos de controle contra factuais na Universidade de São Paulo e o uso de técnicas multivariadas não colocam a situação de realização do pós-doutorado como sendo o principal agente de essencial influência sobre a produtividade docente, mas atuando um item complementar e opcional por ser válido em alguns casos.

Mostrando que não há uma 'receita' ou caminho único a ser seguido o artigo de Castro, Porto e Kannebley (2013) mostra uma variabilidade enorme, dos pós-doutores em relação aos seus pares sem pós-doutorado. A Figura I, extraída de Castro, Porto e Kannebley Júnior (2013), mostra que em vários momentos os docentes com pós-doutorados realizados possuem produção científica nos mesmos patamares ou até mesmo abaixo da produção dos pesquisadores que não realizaram pós-doutorado (linha constante ilustrada na figura - sendo mais visível essa questão nos pontos de 2, 5 e 9 anos após a obtenção do título de doutor).

$\mathrm{E}$, esse fenômeno aconteceu sistematicamente para os recém-doutores (considerados até cinco anos de conclusão do doutorado), entretanto, o 
fenômeno também ocorreu em menor grau com doutores seniores, em que os dados empíricos apontaram que os pares com e sem pós-doutorado, aos nove e aos dezesseis anos após a conclusão do doutorado, possuíam produção equivalentes (Figura I). Não sendo o pós-doutorado essencial para essa diferenciação na carreira.

Figura I Produção de docentes com pós-doutorado em relação aos seus pares sem pós-doutorado e uma curva de estimação que se aproxima dos dados empíricos encontrados na USP (CASTRO; PORTO; KANNEBLEY JR., 2OI3).

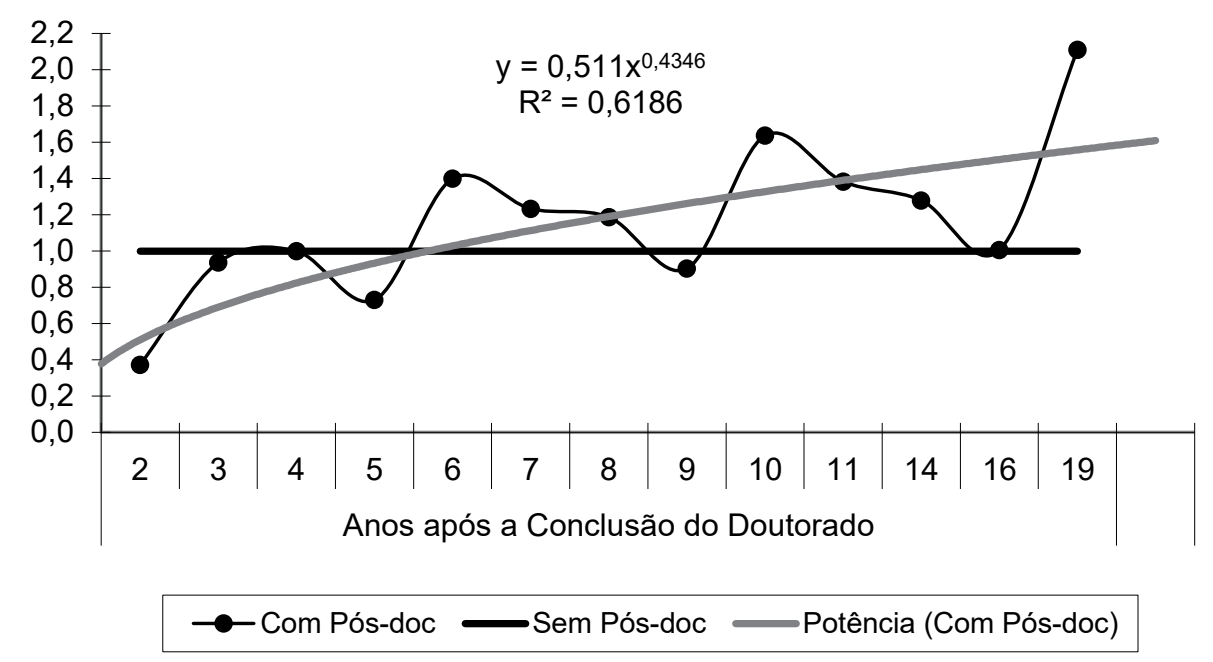

Além desse ponto, os dados obtidos por Castro, Porto e Kannebley Jr. (2013) convergem com os dados de Calvosa, Repossi e Castro (20II) no sentido de que os resultados de influência do pós-doutorado sobre a produção bibliográfica são mais promissores para os pesquisadores seniores.

Nota-se que todo o reportado e expresso na literatura até o momento refere-se exclusivamente os resultados no pós-doutorado sobre as atividades de pesquisa, surgindo uma lacuna e uma questão crucial: Se os estágios pós-doutorais com foco centrado na pesquisa apesar de ter uma influência positiva, não possui um impacto tão grande a ponto de ser decisivo para o sucesso na carreira de pesquisador, qual seria a influência do pós-doutorado 
se considerado de uma forma mais ampla, abrangendo as atividades da pósgraduação que vão além da pesquisa?

Para analisar o impacto do estágio pós-doutoral no sucesso de atividades mais amplas da pós-graduação, fez necessário enxergar que o processo seria maior que 'expandir' a produção bibliográfica, e para avaliar esses quesitos era também necessário criar critérios de avaliação e ponderar essas produções em função de sua importância. Esses critérios fomra defendidos na Tese de Castro (2013) acerca do 'Impacto dos estágios pós-doutorais no exterior: A influência além da produção científica no sistema de pósgraduação', o qual reportamos o seu método, na seção a seguir. 


\section{MÉTODO}

Esta é uma pesquisa quantitativa descritiva, que utilizou como método a análise de dos dados dos sistemas Lattes em um cenário ex ante e ex post. A pesquisa sobre impacto pautou-se também na construção de um índice de desempenho docente que foi inserido no contexto da pesquisa como proposição para a aferição de impacto além das atividades de extensão no âmbito do sistema de produção da pós-graduação, como será descrito a seguir.

\section{OUTRAS PRODUÇÕES DA PÓS-GRADUAÇÃO}

A investigação de impacto, por meio de um índice de desempenho, almejou funcionar como ferramenta de comparação do desempenho entre o "antes" e "depois" do pós-doc, e assim, funcionar como espécie de "repertório de entrada" do docente permitindo comparar, em referência a essa mesma base, se houve diferenças significativas de produção acadêmica. Nesse âmbito seguiu-se próximo ao método com dimensões diferenciadas constante da literatura acerca da investigação acerca do pós-doutorado, com as seguintes dimensões que foram analisadas:

Assessoria a Agências de Fomento

Atuação em Trabalhos de Intercâmbio

Participação como Referee (ou consultor) em Conselhos Editoriais

Participação em Atividades de P\&D (Pesquisa e Desenvolvimento) ou de Cooperação IEs / Setor Produtivo

Produção Artística/Cultural

Produção Técnica

Outras Atividades Técnico-Científicas Listadas pelo Docente

\section{CÔMPUTO DA DIMENSÃO DE FORMA AGREGADA}

Antes de detalhar a forma de se computar as demais produções na pósgraduação, vale frisar que nada impediu do estudo trabalhar, tanto com o cômputo geral por meio do Índice de Desempenho, como em função dos dados levantados, trabalhar-se com o pontual, verificando a variação de itens específicos bem como, o mesmo analisado de forma agrupada; ou 
seja, existia a possibilidade de se trabalhar tanto com o índice, quanto as produções item a item.

A categoria "outras produções da pós-graduação" compreendeu, especialmente, atividades de extensão, constituída por serviços relevantes prestados pelos docentes. Esses serviços dizem respeito à assessoria a agências de fomento, colaboração em redes de pesquisa, participação como referee (ou consultor) em conselhos editoriais de periódicos, participação em atividades de P\&D (Pesquisa e Desenvolvimento) ou de cooperação IEs / Setor Produtivo, produções artísticas e culturais e produção técnica como um todo.

O item "Produção Técnica" seguiu os moldes do definido atualmente no sistema LATTES, abrangendo:

- O desenvolvimento de softwares e/ou de produtos;

- o desenvolvimento de processos inovadores e/ ou de trabalhos técnicos;

- o desenvolvimento de material didático;

- $\quad$ a editoria de periódicos;

- $\quad$ cursos de curta duração ministrados;

- $\quad$ organização de eventos;

- produção de outros tipos de produção técnica (como palestras, manutenção de obras artísticas, etc.), e com um peso maior,

- $\quad$ a obtenção de propriedade intelectual (registros e patentes).

- Proposta para cômputo de outras produções da pós-graduação é apresentada na Tabela I.

Tabela I Cômputo para outras produções da pós-graduação

\begin{tabular}{|c|c|c|}
\hline Cód. & Dimensão Analisada & Forma de Cálculo \\
\hline (A) & Assessoria a Agências de Fomento & $\begin{array}{l}\text { Assessoria a Agências de Fomento = [ } 2 \text { (Ag. } \\
\text { Nacional })+1(\text { Ag. Estadual })]\end{array}$ \\
\hline (B) & $\begin{array}{l}\text { Atuação em Redes de Pesquisa e } \\
\text { Intercâmbio }\end{array}$ & $\begin{array}{l}\text { Atuação em Redes de Pesq. }=\text { [ 5(rede internacional } \\
+3 \text { (rede de IES nac.) }]\end{array}$ \\
\hline (C) & $\begin{array}{l}\text { Atividades de P\&D ou de Cooperação } \\
\text { IES/Setor Produtivo }\end{array}$ & $\begin{array}{l}\text { Participação em atividades de P\&D ou de } \\
\text { Cooperação IES/Setor Produtivo = 3(Ativid. } \\
\text { Desenv.) }\end{array}$ \\
\hline (D) & $\begin{array}{l}\text { Participação como Referee (ou } \\
\text { consultor) em Conselhos Editoriais }\end{array}$ & - \\
\hline (E) & Produção Artística/Cultural & - \\
\hline
\end{tabular}




\begin{tabular}{|lll|}
\hline Cód. & Dimensão Analisada & Forma de Cálculo \\
\hline (F) & Produção Técnica & $\begin{array}{l}\text { Produção Técnica }=\text { [ 3(Desenv. Aplicativo + Desenv. } \\
\text { Produto + Org. de Evento) + 2(Desenv. Técnico } \\
\text { + Desenv. Processo + Curso de curta duração + } \\
\text { Desenv Mat Didático + Editoria) + 5(Registros ou } \\
\end{array}$ \\
& $\begin{array}{l}\text { Patentes) + 1(Outra Prod.) ] } \\
\text { (G) } \quad \begin{array}{l}\text { Outras Atividades Técnicos Científicas } \\
\text { Listadas pelo Docente }\end{array}\end{array}$ \\
\hline
\end{tabular}

Em relação a patentes, cabe o parêntesis que: algumas áreas, a exemplo da Biotecnologia, estão propensas a fornece-lhe um peso relacionado com publicações (uma patente equivalente a $x$ publicações nível Qualis y). Critérios esses ainda em discussão, no momento essa forma de cálculo específico nos diversos comitês não é uma regra geral, mas enquanto "embrião", abre espaço junto às comissões de áreas, como possibilidades de novas tendências.

Após o cálculo de cada dimensão conforme ilustra a Tabela I, o score dessas atividades é a soma de cada um dos elementos constitutivos.

Assim: "outras produções da Pós-Graduação" $=\mathrm{A}+\mathrm{B}+\mathrm{C}+\mathrm{D}+\mathrm{E}+\mathrm{F}+\mathrm{G}$.

\section{ABRANGÊNCIA DO ESTUDO}

O índice foi calculado para a dimensão OP - Outras Produções da Pós-Graduação e para cada grande área do conhecimento, a saber: Sociais Aplicadas, Biológicas, Engenharias, Ciências da Saúde, Humanidades, Exatas e da Terra, Agrárias, Letras, Linguística, Artes e Multidisciplinares (vide Tabela 2). 
Tabela 2 Detalhamento da composição das grandes áreas

\begin{tabular}{|c|c|c|}
\hline Biológicas & Sociais Aplicadas & Engenharias \\
\hline $\begin{array}{l}\text { Biologia Geral } \\
\text { Biofísica } \\
\text { Bioquímica } \\
\text { Botânica } \\
\text { Ecologia } \\
\text { Farmacologia } \\
\text { Fisiologia } \\
\text { Genética e Melhoramento } \\
\text { Imunologia } \\
\text { Microbiologia } \\
\text { Morfologia } \\
\text { Parasitologia } \\
\text { Zoologia }\end{array}$ & $\begin{array}{l}\text { Administração } \\
\text { Arquitetura e Urbanismo } \\
\text { Ciência da Informação } \\
\text { Comunicação } \\
\text { Contábeis } \\
\text { Demografia } \\
\text { Desenho Industrial } \\
\text { Direito } \\
\text { Economia } \\
\text { Museologia } \\
\text { Planejamento Urb.e Regional } \\
\text { Serviço Social } \\
\text { Turismo }\end{array}$ & $\begin{array}{l}\text { Eng. Aeroespacial } \\
\text { Eng. Biomédica } \\
\text { Eng. Civil } \\
\text { Eng. de Materiais } \\
\text { Eng. de Minas } \\
\text { Eng. de Produção } \\
\text { Eng. de Transportes } \\
\text { Eng. Elétrica } \\
\text { Eng. Mecânica } \\
\text { Eng. Oceânica } \\
\text { Eng. Nuclear } \\
\text { Eng. Química } \\
\text { Eng. Sanitária }\end{array}$ \\
\hline Saúde & Humanas & Exatas e da Terra \\
\hline $\begin{array}{l}\text { Educação Física } \\
\text { Enfermagem } \\
\text { Farmácia } \\
\text { Fisioterapia } \\
\text { Terapia Ocupacional } \\
\text { Fonoaudiologia } \\
\text { Medicina } \\
\text { Nutrição } \\
\text { Odontologia } \\
\text { Saúde Coletiva }\end{array}$ & $\begin{array}{l}\text { Antropologia } \\
\text { Arqueologia } \\
\text { Ciência Política } \\
\text { Educação } \\
\text { Filosofia } \\
\text { Geografia } \\
\text { História } \\
\text { Psicologia } \\
\text { Sociologia } \\
\text { Teologia }\end{array}$ & $\begin{array}{l}\text { Astronomia } \\
\text { Computação } \\
\text { Física } \\
\text { Química } \\
\text { Geociências } \\
\text { Matemática } \\
\text { Oceanografia } \\
\text { Estatística }\end{array}$ \\
\hline Agrárias & Letras, Linguística e Artes & Multidisciplinar \\
\hline $\begin{array}{l}\text { Agronomia } \\
\text { Engenharia Agrícola } \\
\text { Engenharia Florestal } \\
\text { Engenharia de Pesca } \\
\text { Medicina Veterinária } \\
\text { Tecnologia de Alimentos } \\
\text { Zootecnia }\end{array}$ & $\begin{array}{l}\text { Artes } \\
\text { Letras } \\
\text { Linguística }\end{array}$ & $\begin{array}{l}\text { Áreas de Pós-Graduação } \\
\text { Multidisciplinares, conforme } \\
\text { classificados pelos comitês de } \\
\text { avaliação/CAPES. }\end{array}$ \\
\hline
\end{tabular}

Fonte: Informações constantes no sítio da CAPEs (2014). 


\section{PROCEDIMENTOS}

A meta era realizar a distribuição do convite de avaliação de forma censitária, tendo como escopo todo o universo de ex-bolsistas da Capes desde a criação do programa de pós-doutorado (em 1996) até o ano de 2008 (quando o programa foi dividido em dois - pesquisa pós-doutoral e estágio sênior, inclusive com valores de bolsas diferenciados).

Dos 3.820 ex-bolsistas do quadro da Capes, muitos não compuseram a população por motivos adversos, como: o mesmo docente ter recebido bolsa de pós-doutorado em dois (ou mais) diferentes momentos, egresso que não possuía vínculo empregatício, docentes que não integravam o sistema de pós-graduação, seja por trabalhar apenas na graduação, seja por ter assumido cargos administrativos na reitoria com desligamento voluntário concomitante, falecimento, aposentadoria e outras questões adversas, [pasmem] entre elas o fato de haver docentes que (ainda) não possuíam currículos on-line constantes do sistema Lattes e informações incompletas ou desatualizadas no banco de dados da Capes, que impossibilitavam o contato.

De 1996, quando da criação do programa, até 2008; das 3.820 bolsas de pós-doutorado no exterior concedidas pela Capes, verificou-se que I.034 diziam respeito a bolsistas egressos que não trabalhavam inseridos na pósgraduação por diversos motivos: por atuarem apenas na graduação (334), por estarem lotados em instâncias administrativas da IES que exigiam dedicação exclusiva (6) ou por não possuírem vínculo empregatício (694). Somem-se, ainda, 93 que estavam duplicados no banco de dados, pois haviam recebido bolsa em dois ou mais momentos, nove que já haviam se aposentado e onze que haviam falecido, bem como, I08 casos com currículos não encontrados ou dados desatualizados/incompletos. Não se considerando esses casos relatados, configurou-se, então, uma população de $\mathbf{2 . 5 6 5}$ doutores com pósdoutorado realizado e efetivos para os objetivos dessa pesquisa.

\section{AMOSTRA}

Da população de 2.565 doutores, 978 responderam ao e-mail convite respondendo a um breve questionário e após a atualização do currículo 
Lattes, nos autorizavam à verificação dos seus dados de produção após a sua efetiva atualização.

A investigação de impacto alicerçado pelo índice de produção docente mais ampla na pós-graduação foi realizada com base em uma amostra não probabilística de voluntários, com a perspectiva de que fizeram parte da amostra somente os docentes que responderem à convocação por e-mail. Estratégia adotada para assim obter maior alcance na aferição de impacto, convém lembrar que muitos doutores pesquisas sequer atualizavam nos seus currículos, os dados de produção mais amplas [além da produção bibliográfica], por considerar que as mesmas não seriam objetos de análise de comitês de avaliação.

Em relação ao gênero, a amostra de docentes que realizaram estágios pós-doutorais no exterior totalizou 978 docentes pesquisadores, sendo 395 docentes $(40,4 \%)$ do gênero feminino e 583 docentes (59,6\%) do gênero masculino. Os docentes e suas respectivas áreas de atuação acadêmica encontra-se conforme disposto no Anexo I. No que diz respeito à distribuição dos participantes e suas respectivas Unidades da Federação, os dados ilustrados na Tabela 3 mostram que quase um terço $(30,1 \%)$ dos egressos respondentes foram do estado de São Paulo.

Tabela 3 Distribuição dos docentes respondentes pelas Unidades da Federação

\begin{tabular}{|lll|}
\hline UF & Número de respondentes & Porcentagem \\
\hline Pará & 1 & $0,1 \%$ \\
\hline Amazonas & 4 & $0,4 \%$ \\
\hline Mato Grosso do Sul & 4 & $0,4 \%$ \\
\hline Mato Grosso & 7 & $0,7 \%$ \\
\hline Pernambuco & 8 & $0,8 \%$ \\
\hline Alagoas & 10 & $1 \%$ \\
\hline Rio Grande do Norte & 10 & $1 \%$ \\
\hline Acre & 13 & $1,3 \%$ \\
\hline Bahia & 14 & $1,4 \%$ \\
\hline Ceará & 14 & $1,4 \%$ \\
\hline Santa Catarina & 25 & $2,6 \%$ \\
\hline
\end{tabular}




\begin{tabular}{|lll|}
\hline UF & Número de respondentes & Porcentagem \\
\hline Rondônia & 27 & $2,8 \%$ \\
\hline Paraná & 28 & $2,9 \%$ \\
\hline Distrito Federal & 29 & $3 \%$ \\
\hline Rio Grande do Sul & 32 & $3,3 \%$ \\
\hline Rio de Janeiro & 48 & $4,9 \%$ \\
\hline Paraíba & 59 & $6 \%$ \\
\hline Sergipe & 65 & $6,6 \%$ \\
\hline Goiás & 117 & $12,0 \%$ \\
\hline Minas Gerais & 168 & $17,2 \%$ \\
\hline São Paulo & 294 & $30,1 \%$ \\
\hline- & 1 & $0,1 \%$ \\
\hline Total & 978 & $100 \%$ \\
\hline
\end{tabular}

Vale pontuar que, dos estados brasileiros na sua totalidade, apenas os estados de Tocantins, Espírito Santo, Roraima, Maranhão e Piauí encontram-se não representados pela amostra de docentes. E, em uma situação inversa, notase que em alguns estados como Acre, Sergipe, Paraíba e Goiás, houve uma configuração de retorno dos questionários bastante superior e expressiva. O Acre, por exemplo, teve a participação de um número de respondentes praticamente com o mesmo patamar que o estado da Bahia; Sergipe, Paraíba e Goiás foram superiores ao Rio de Janeiro no número absoluto de retorno de aceitação para participar do atual levantamento, portanto com esta configuração posta, essas Unidades da Federação encontram-se superrepresentadas pela devolução dos Lattes atualizados pelos docentes.

Em relação às regiões geográficas a amostra mostrou-se bastante equilibrada e cobrindo todas as regiões do país (Tabela 4), com uma composição próxima da regionalidade da distribuição de recursos públicos que na última década foram destinados ao desenvolvimento de recursos humanos (CAPES). 
Tabela 4 Distribuição da amostra por regiões geográficas e comparativo com o perfil dos investimentos públicos realizados pela Capes

\begin{tabular}{|llll|}
\hline Região do Pais & Frequência & $\%$ & Comparativo com inves-timentos da Capes no pais \\
\hline Sudeste & 510 & $52,1 \%$ & $48 \%$ \\
\hline Nordeste & 184 & $18,8 \%$ & $21 \%$ \\
\hline Centro-Oeste & 157 & $16,1 \%$ & $11 \%$ \\
\hline Sul & 85 & $8,7 \%$ & $16 \%$ \\
\hline Norte & 41 & $4,2 \%$ & $4 \%$ \\
\hline - & 1 & $0,1 \%$ & - \\
\hline Total & $\mathrm{n}=978$ & $100,0 \%$ & \\
\hline
\end{tabular}

Fonte: Dados da pesquisa e da Coordenação de Aperfeiçoamento de Pessoal de Nível Superior (CAPEs).

A distribuição dos docentes participantes da pesquisa, de acordo com o ano de obtenção do título de doutorado, indicou uma distribuição com uma moda de conclusão do curso de doutorado no ano de 1995, havendo também o desenho de um pico em conjunto do número de docentes com título de doutorado obtido entre os anos de 1994 e 1999 (vide Figura 2).

A distribuição do ano de término do doutorado dos docentes que realizaram o estágio pós-doutoral pertencentes à amostra (Figura 2), possuiu como média o ano de 1995, com desvio padrão de 5,62 anos; tendo o mínimo de 1971, o máximo de 2008 e uma mediana de 1996. Indicando uma concentração na porção central do gráfico e mostrando uma distribuição com tendência de concentração da realização do pós-doutorado para os docentes com conclusões do doutorado a partir de meados da década de 90. 
Figura 2 Distribuição dos docentes da amostra e o ano de obtenção do título de doutorado

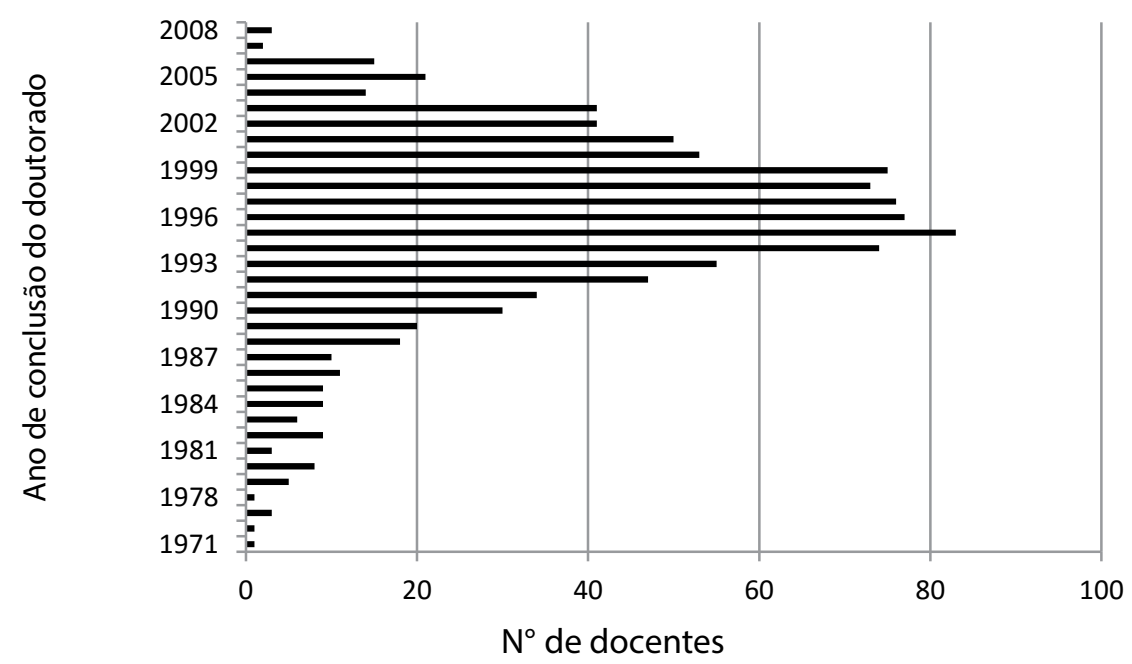

Em relação ao ano de realização do último pós-doutorado pelos docentes que participaram deste levantamento nota-se que nos quatro últimos anos da década de 9o, quando do início do programa de fomento, há uma procura bem menor por parte dos docentes, havendo o aumento expressivo dos estágios a partir dos anos 2000. Com um grande sobressalto de 200I para 2002, patamar esse que se manteve praticamente constante de 2003 a 2005, havendo novamente um sobressalto com crescimento que passa a ser praticamente exponencial a partir do ano de 2006 (Figura 3). 
Figura 3 Distribuição do ano do último pós-doutorado realizado pelos docentes que participaram da pesquisa

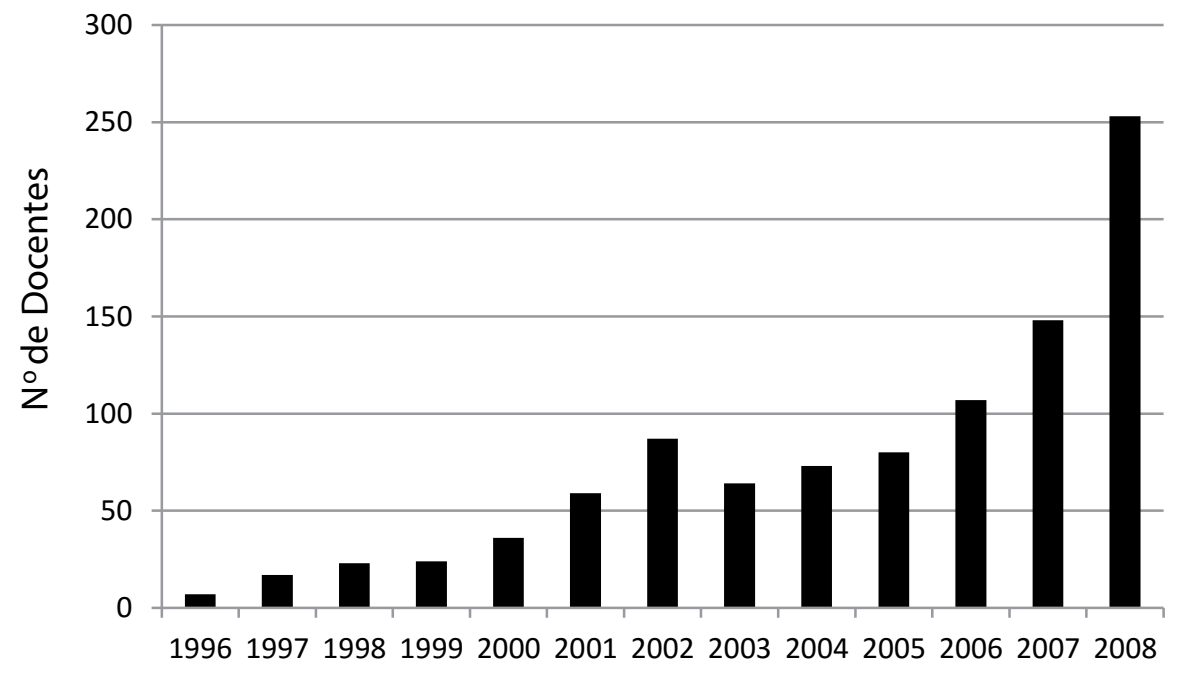

Este desenho da amostra em relação ao ano de realização do pós-doutorado no exterior ilustrado na Figura 3 teve um perfil bastante semelhante à configuração estabelecida para o Programa de Estágio Pós-doutoral no Exterior conforme expresso em Castro e Porto (2012) e, assim, ambas as informações, a do universo e da amostra, possuíram perfis bastante semelhante ambas caminhando numa mesma direção e sentido.

A Figura 4 ilustra graficamente uma idade relativa, considerando-se a idade que o pesquisador possuía quando realizou o pós-doutorado no exterior. Caracterizou-se que 46 docentes não responderam a essa questão e a figura traz a faixa etária dos participantes e ilustra em termos percentuais a idade de uma forma categorizada. 
Figura 4 Faixa etária dos respondentes quando da realização do estágio pós-doutoral

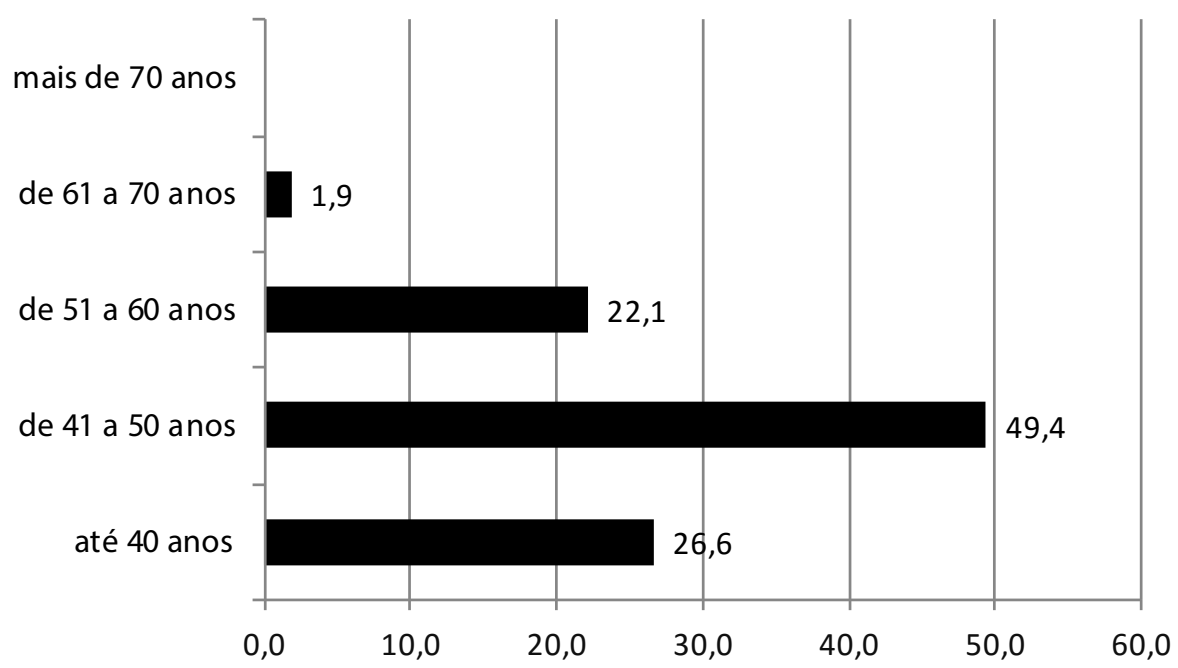

Quando considerado a idade que o docente possuía quando realizou o pósdoutorado essa disposição na Figura 4 indica uma concentração, com pouca dispersão e indica uma distribuição com moda de realização da capacitação pós-doutoral concentrada e uma idade média de 42 anos, pontuando de uma forma mais nítida que quase metade dos docentes quando realizou o pós-doutorado estava na faixa etária dos $4 \mathrm{I}$ aos 5050 anos. 


\section{RESULTADOS E DISCUSSÃO}

Considerando-se que participaram do levantamento apenas docentes que estavam com o currículo Lattes devidamente atualizado, conforme descrito anteriormente, em primeira instância chama a atenção que em relação a Outras Produções da pós-graduação, que foram agrupadas no composito OP, apesar da grande variabilidade de atividades e do largo escopo em relação aos itens que o compõem, os resultados da pesquisa mostram ser esse um lado relegado e esquecido por muitos dos docentes pesquisados. Pois Io6 docentes não registraram no seu currículo Lattes nenhuma atividade técnica desenvolvida durante toda a sua carreira acadêmica.

Essa é a ocorrência que mais se destaca. Apesar da composição do índice OP abranger serviços amplos e diversos como a assessoria a órgãos de fomento, a emissão de pareceres, desenvolvimento de produtos, aperfeiçoamento de processos, cursos de curta duração, registros de software, patentes, desenvolvimento de material didático, participação em atividades de cooperação com o setor produtivo, organização de eventos, editoria e outras atividades técnico-científicas relevantes listadas pelo docente. Houve 106 docentes, o que corresponde a 10,8\% dos pesquisados, que não desenvolveram nenhuma dessas atividades antes de realizar o pós-doutorado no exterior e continuaram não desenvolvendo nenhuma dessas atividades após a realização do estágio pós-doutoral no exterior.

Esse dado em si já é um forte indicador que a influência do estágio pósdoutoral sobre atividades mais amplas deixa a desejar. Soma-se a isso que além destes ro6 professores que registraram pontuação zero ao longo de toda a sua carreira acadêmica - e a realização do pós-doutorado não ajudou a mudar esse quadro; houve também o registro de 59 professores (+ $6 \%$ da amostra) que possuíam alguma produção técnica, mesmo que ínfima, antes da realização do estágio pós-doutoral no exterior e no cenário ex post essa produção praticamente deixou de existir, apresentando queda de mais de $80 \%$ nos escores obtidos por meio do índice de desempenho em outras produções da pós-graduação, antes e depois do pós-doutorado.

Um cenário nada animador. 
Conforme a Figura 5 apesar da média elevada, certamente provocada pelos outliers, houve a tendência clara de predominância das variações negativas e também das não variações (impacto nulo), a moda igual a zero indica que a influência nula é a situação que mais se repete, no que diz respeito ao pós-doutorado no exterior e algum efeito sobre produções mais amplas no sistema de pós-graduação.

Por outro lado, apensar da predominância claramente não deixar dúvidas que o cenário da produção de extensão na pós-graduação deixa mesmo a desejar e necessita de melhorias; e a realização de um pós-doutorado no exterior, atualmente não parece ser o caminho mais adequado para que essas melhorias aconteçam, há que se observar que pelo valor da mediana há a indicação que pelo menos em mais de $50 \%$ dos casos houve algum impacto e variação da produção na extensão antes e depois da atividade pós-doutoral no exterior (Figura 5).

$\mathrm{Na}$ busca de respostas para quais seriam os preditores desse impacto, impacto esse de certa forma até destoante do cenário global, dentre as tentativas de equacioná-las por meio de diversos modelos de regressão estas não chegaram a outputs satisfatórios. Os modelos de regressão logística, incluindo-se o passo a passo progressivo, não passaram dos $9 \%$ de acurácia, os modelos de regressão múltipla também mostraram equações com baixo poder de predição e explicando no máximo $5 \%$ da variância. 
Figura 5 Histograma mostrando a frequência/distribuição do impacto do pós-doutorado no exterior medido por meio da variação da produção técnica

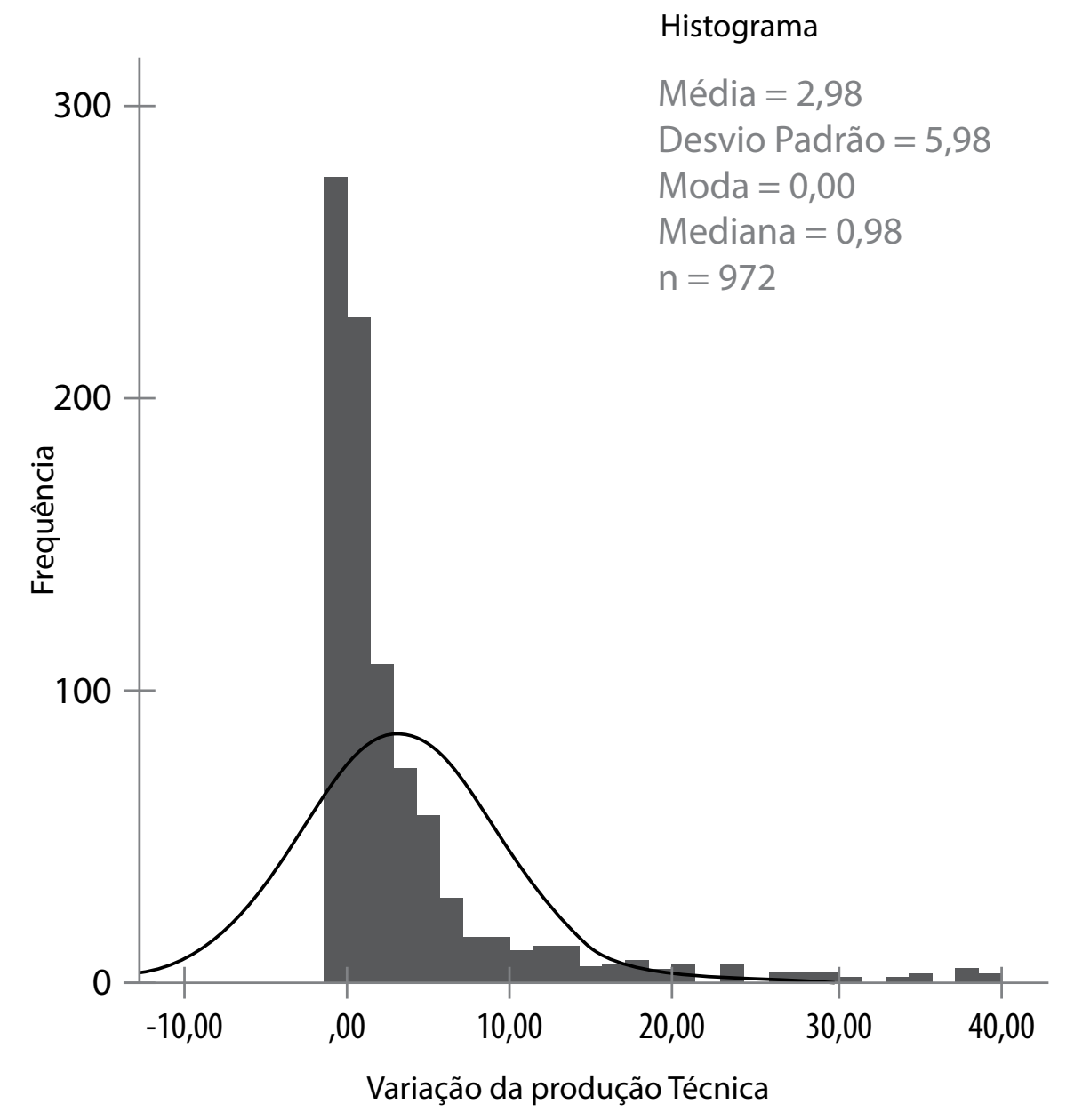

Dessa forma, os resultados apontam que não há como estabelecer uma relação de predição de uma forma mais nítida ou definida. Ao ter-se em perspectiva as variáveis que foram mensuradas neste levantamento, a questão da produção técnica vai além das variáveis que foram objetos de análise na atual pesquisa (vide detalhamento das variáveis na Tabela 5). 
Tabela 5 Quadro geral acerca da configuração das médias da variável "pontos/ano" (OP) em relação a situação ex ante e ex post da realização do pós-doutorado e as demais variáveis explanatórias

\begin{tabular}{|c|c|c|c|c|}
\hline Variável & & $\begin{array}{l}\text { OP média pontos/ano } \\
\text { Antes }\end{array}$ & $\begin{array}{l}\text { OP média pontos/ano } \\
\text { Depois }\end{array}$ & $\begin{array}{l}\text { Variação } \\
\text { Média (') }\end{array}$ \\
\hline \multirow[t]{2}{*}{ Gênero } & Masculino & 3,08 & 6,82 & 2,20 \\
\hline & Feminino & 3,57 & 9,33 & 3,31 \\
\hline \multirow[t]{4}{*}{ Faixa etária relativa } & Até 40 anos & 2,47 & 7,35 & 3,37 \\
\hline & De 41 a 50 anos & 3,39 & 7,91 & 2,52 \\
\hline & De 51 a 60 anos & 3,88 & 8,52 & 2,08 \\
\hline & De 61 a 70 anos & 3,80 & 5,62 & 1,85 \\
\hline \multirow[t]{9}{*}{ Grande Área } & Agrárias & 4,16 & 6,25 & 1,31 \\
\hline & Biológicas & 2,39 & 6,41 & 3,32 \\
\hline & Engenharias & 2,33 & 4,13 & 1,43 \\
\hline & Exatas e da Terra & 2,00 & 3,99 & 2,47 \\
\hline & Humanas & 4,19 & 12,18 & 3,86 \\
\hline & Letras, Linguística e Artes & 5,35 & 11,39 & 2,70 \\
\hline & Multidisciplinar & 3,19 & 9,33 & 4,26 \\
\hline & Saúde & 2,17 & 6,17 & 3,73 \\
\hline & Sociais Aplicadas & 4,21 & 10,02 & 3,16 \\
\hline \multirow{4}{*}{$\begin{array}{l}\text { Duração do pós- } \\
\text { doutorado }\end{array}$} & $<$ que 6 meses & 4,43 & 10,73 & 2,27 \\
\hline & 6 a 11 meses & 3,22 & 8,34 & 3,43 \\
\hline & 12 meses & 2,91 & 6,57 & 3,02 \\
\hline & $>$ que 12 meses & 1,18 & 1,08 & $-0,08$ \\
\hline \multirow{4}{*}{$\begin{array}{l}\text { № de Pós-Docs } \\
\text { Realizados }\end{array}$} & 1 & 3,27 & 7,72 & 2,96 \\
\hline & 2 & 3,21 & 7,48 & 2,94 \\
\hline & 3 & 3,64 & 10,20 & 3,62 \\
\hline & Mais de 3 & 3,41 & 12,18 & 2,43 \\
\hline \multirow{4}{*}{$\begin{array}{l}\text { Anos após } \\
\text { Conclusão do } \\
\text { Doutorado }\end{array}$} & Menor que 4 anos & 1,76 & 6,82 & 3,32 \\
\hline & 4 a 8 anos & 2,92 & 7,65 & 2,02 \\
\hline & $8-12$ anos & 3,70 & 8,56 & 2,14 \\
\hline & Mais de 12 anos & 4,06 & 7,26 & 1,96 \\
\hline
\end{tabular}

No entanto, dentro do contexto das variáveis que foram coletadas (Tabela 5) embora não se tenha encontrado preditores, cabe apontar que registrou-se uma relação de diferenciação da variação técnica de acordo com a área de 
atuação do docente (Figura 6) e encontrou-se uma associação positiva entre a variação da produção técnica e as reações dos colegas do docente ao pósdoutorado realizado (Figura 7 - vide Anexo II para maior detalhamento). Nesses últimos dois casos, ocorrem situações que abrem o caminho de pesquisa para que se investiguem no futuro outras variáveis que aprofundem e que coletem mais aspectos qualitativos ou de cunho psicossocial, que pelo que se sugere, parecem interferir nesse processo.

Em relação à grande área do conhecimento, há uma média de variação técnica menor para as grandes áreas de Agrárias e de Engenharias - que deveriam ser áreas aplicadas de prestação de serviços, mas isso não é uma regra para todas as engenharias, conforme pode-se observar na Figura 6, algumas áreas das engenharias possuem uma média mais elevada e diferenciada, bem como, algumas áreas do conhecimento classificadas pela Capes na grande área de Agrárias, também conseguem se destacar, a exemplo da medicina veterinária, engenharia florestal e engenharia agrícola.

Essas diferenças de médias apresentadas pelas áreas (Figura 6) foram submetidas por meio da ANOva ao teste de diferenças médias entre grupos combinados, encontrou-se uma probabilidade associada ( $p$-value $=0,0$ or $)$, que mostra que há pouca possibilidade das médias encontradas e diferenciadas para algumas áreas terem sido decorrentes de erro amostral.

Algumas áreas do conhecimento mostraram-se como mais propicias para a visualização de impacto do pós-doutorado na extensão por partes dos seus docentes. Entre as “campeões” estão as áreas de Biologia Geral, Ciência Política e Morfologia, acompanhadas das áreas de Astronomia, Ciência da Informação, Comunicação, Enfermagem, Engenharia Agrícola, Filosofia, Fisioterapia, Fonoaudiologia, Genética e Zoologia. Nessas áreas em maior grau e em um grau um pouco menor nas demais áreas listadas no gráfico superior da Figura 6, a percepção de que o pós-doutorado pode ser útil para a extensão mostrou-se diferenciada positivamente em relação às demais áreas do conhecimento. 
Figura 6 Áreas do conhecimento agrupadas em relação à média diferenciada para com o impacto do pós-doutorado em atividades técnicas e de extensão na pós-graduação

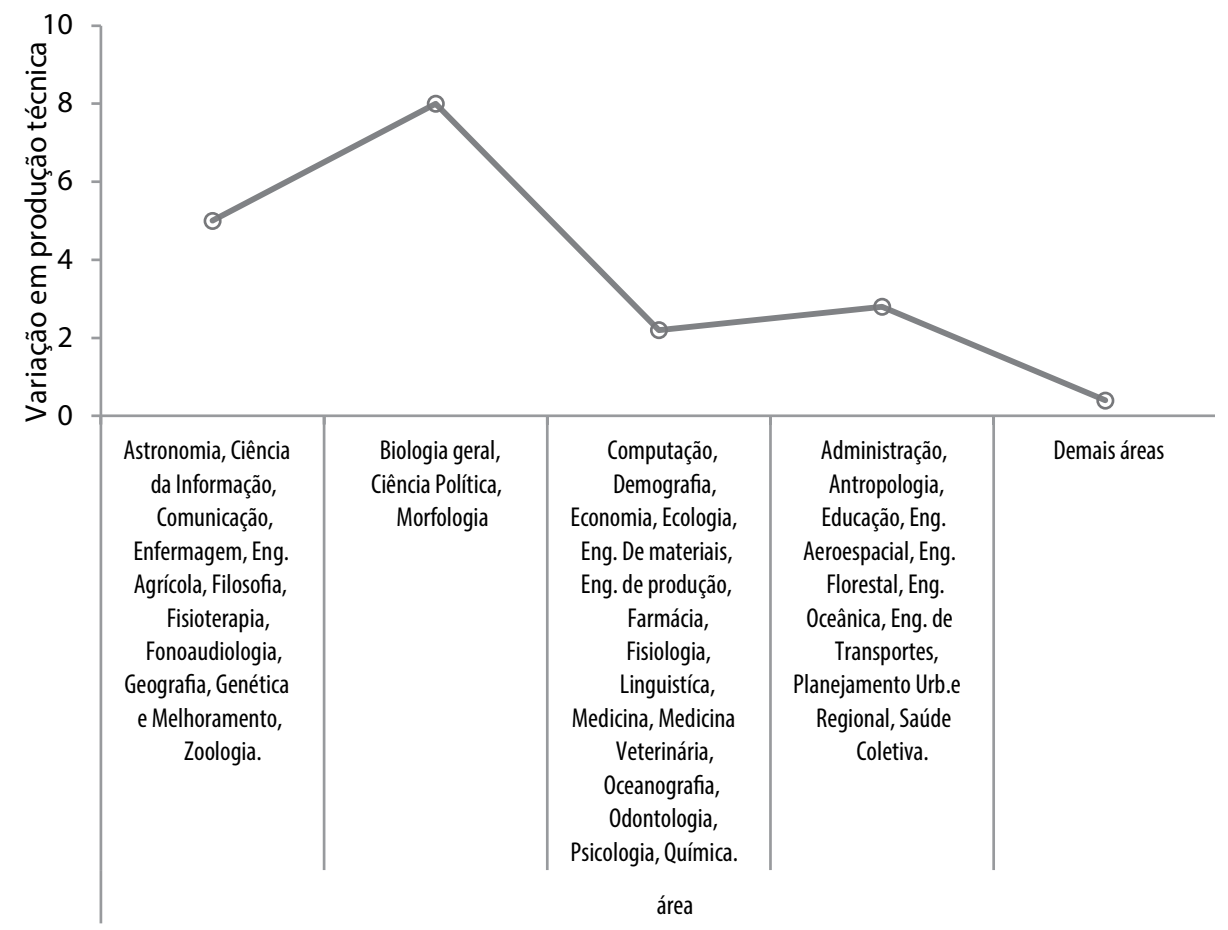

Embora com um impacto menor em relação a estas áreas citadas, nota-se na Figura 6 que há outras áreas do conhecimento que apresentam uma influência positiva do pós-doutorado sobre as atividades técnicas e de extensão, entre elas a área de administração. O que pode ser considerado louvável, considerandose o cenário acadêmico registrado e que tende a um impacto nulo.

Em relação à reação ao pós-doutorado realizado (vide Figura 7), mostrase que a satisfação com o pós-doutorado (do ponto de vista dos seus pares) e a insatisfação com o pós-doutorado realizado (também do ponto de vista da heteroavaliação dos pares), mantêm relação com a ocorrência maior de produção técnica após a realização do pós-doutorado. Mas a boa reação 
dos docentes, não é suficiente para explicar o fenômeno, afinal como dito anteriormente houve inúmeros casos de docentes com produção técnica nula e que mantiveram esse status independentemente de terem gostado, mostrarem-se satisfeitos e terem reagido bem ao pós-doutorado.

No entanto, certamente (Figura 7), a dimensão social tão discutida na área de Treinamento, Desenvolvimento e Educação, ou seja, capacitação, mostrouse em princípio realmente associada e com relação importante com essa questão, uma boa reação dos colegas dos docentes aparentemente favorece a produção técnica na pós-graduação, mas talvez os resultados não sejam tão contundentes talvez por que ela ocorra em interação com outros aspectos qualitativos que não foram aqui coletados, como por exemplo, a natureza dos conteúdos trabalhados no pós-doutorado, o perfil acadêmico do colaborador no exterior, os interesses acadêmicos envolvidos, bem como em especial, a motivação inicial do docente para a realização do pós-doutorado no exterior.

Mas de qualquer maneira, fica o registro da variável de natureza psicossocial que mostrou ter uma parcela de contribuição que foi a reação dos pares/colegas após a realização do pós-doutorado (Figura 7).

Figura 7 Reação dos colegas após o pós-doutorado realizado e médias da variação do índice de desempenho em produção técnica dos docentes

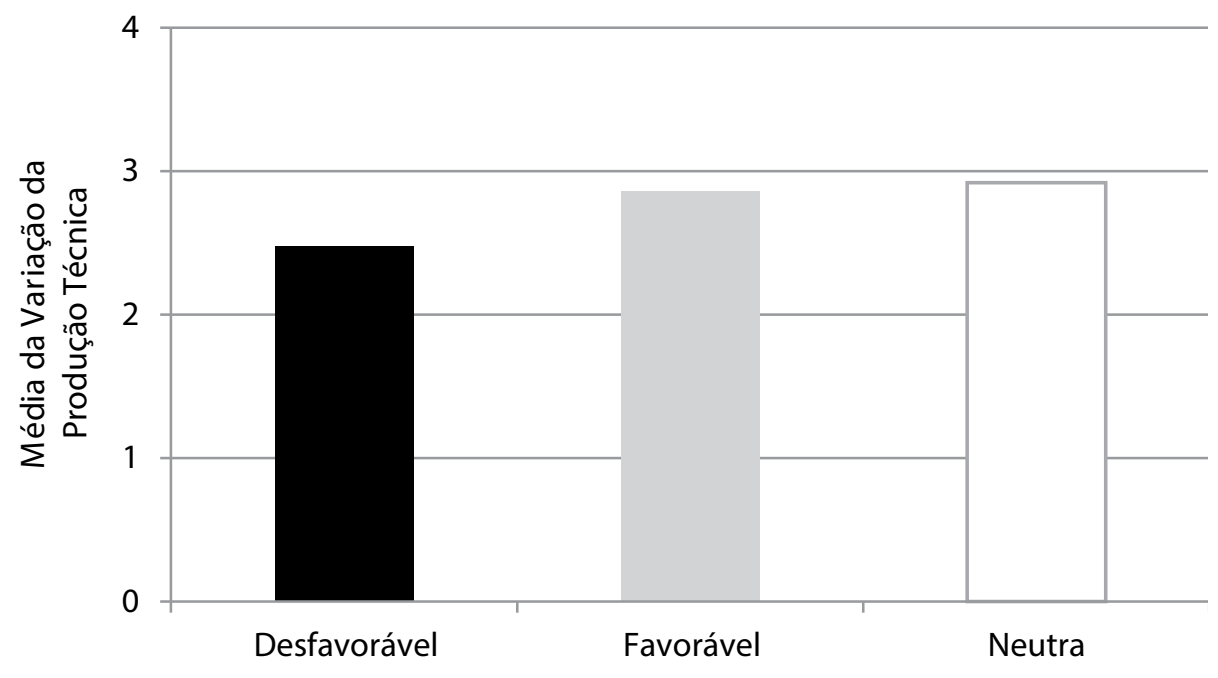


Essa variável 'reação dos colegas' mostrou-se com uma correlação situada entre fraca e moderada $(r=0,369)$ e as diferenças de médias apontadas na Figura 7 entre os docentes que percebem a reação dos colegas como desfavoráveis $(n=163)$ e os docentes que percebem a reação dos colegas como favoráveis $(\mathrm{n}=615)$, foram submetidas ao Teste $t$ de amostras independentes (Independent-samples $T$ Test) e apresentaram um resultado apontando que essas diferenças apenas podem ser consideradas significativas com um intervalo de $90 \%$ de confiança $(p$ value $=0,063$ ), o que mostra que as reações dos colegas, como pode-se notar visualmente, contribuem para uma performance diferenciada, mas possuem uma influência leve sobre o comportamento da produção da técnica e extensão no contexto pósdoutoral. 


\section{CONSIDERAÇÕES FINAIS}

Além da produção bibliográfica, em síntese, os resultados mensurados pelo meio do índice no compósito OP - Outras produções, em suas vertentes, apontam que o pós-doutorado no exterior consegue desenhar um razoável e mediano impacto sobre o desempenho do docente, no que diz respeito a publicações científicas (CASTRO; PORTO, 2008, 20IO, 20I2; CALVOSA; REPOSSI; CASTRO, 2OII; CASTRO; PORTO; n 2OI3,), mas não consegue atuar de forma adequada como agente propulsor da melhoria e expansão das demais produções da pós-graduação, em sua maioria voltadas para as atividades de extensão.

De uma forma geral, o que sobressai quanto à questão da produção técnica e de extensão pelo conjunto dos resultados desta pesquisa, nada animadores, é que as atividades que vão além da produção bibliográfica parecem estar atualmente como um lado esquecido do sistema de pós-graduação, e a sua melhoria pode até ocorrer mediante a utilização do pós-doutorado como instrumento - deu certo em alguns casos, mas parece necessitar de um panorama mais integrado que envolva as políticas públicas de incentivo por parte do Estado, as políticas e as diretrizes internas das instituições de ensino superior, a motivação e posicionamento de cada docente, e principalmente a valorização dessas atividades no próprio sistema de avaliação, para que as mesmas possuam o devido status que merecem diante da sua importância e relevância para o funcionamento do sistema de pós-graduação.

Como reflexão e até mesmo motivação para mudança, fica a questão sobre o que enquanto acadêmicos queremos para o futuro da pós-graduação brasileira? Ensino? Pesquisa? Nada mais? 


\section{REFERÊNCIAS}

BRASIL. Lei 9.394/96, de 20 de dezembro de 1996. Estabelece as diretrizes e bases da educação nacional. Publicada no DOU de 23.12.96; disponibilizado em: $<$ http:/ / www. planalto.gov.br/>. Acesso em: 11/2011.

CALVOSA, M.V.D.; REPOSSI, M. G.; CASTRO, P. M. R. Avaliação de resultados da capacitação docente: O Pós-doutorado na Universidade Federal Fluminense sob a ótica da Produção Científica e Bibliográfica. Revista da Avaliação da Educação Superior. v. 16, n. 1, p. 99-122. 2011.

CAMARGO, M. R. R. M.; MIGUEL, J. C.; ZANATA, E. M. A extensão universitária como ponte do fazer, do aprender, do pensar. Cadernos Cedes, v. 35, n. 96, p. 257-276, 2015.

CASTRO. P. M. R. Impacto dos estágios pós-doutorais no exterior: a influência além da produção científica no sistema de pós-graduação. 222f, 2013. Tese (doutorado). Faculdade de Economia, Administração e Contabilidade, Universidade de São Paulo, São Paulo.

CASTRO, P. M. R.; PORTO, G. S. Retorno ao Exterior Vale a Pena? A questão dos estágios pós-doutorais sob a perspectiva da produção em C\&T. Organizações \& Sociedade, v. 15, n. 47, p. 155-173. 2008.

CASTRO, P. M. R.; PORTO, G. S. Análise exploratória sobre avaliação e mensuração de resultados da capacitação via estágios pós-doutorais: heterogeneidade entre grandes áreas do conhecimento? Revista de Administração da USP, v. 45, n. 1, p. 43-56, 2010.

CASTRO, P. M. R.; PORTO, G. S.; KANNEBLEY JÚNIOR, S. Pós-doutorado, Essencial ou Opcional? Revista da Avaliação da Educação Superior, v.18, n.3, p.773-801, 2013.

CASTRO, P. M. R.; PORTO, G. S. Avaliação de resultados da capacitação via estágios pós-doutorais: Breves notas sobre a produção científica em periódicos. Ensaio - Fundação Cesgranrio, v. 20, n. 1, p. 51-72, 2012.

CORAIOLA, D. M.; BARATTER M. A.; TAKAHASHI, A. R. W.; MAY, M. R. Pósdoutorado na formação dos docentes de programas de pós-graduação em administração no Brasil - Perfil e configuração. Administração: Ensino e pesquisa, v. 14, n. 4, p. 725-758, 2013.

FERNANDES, M. C.; SILVA, L. M. S.; MACHADO, A. L. G; MOREIRA, T. M. M. Universidade e a extensão universitária. Educação em Revista, v. 28, n. 4, p. 169-194, 2012.

GOERGEN, P. Ciência, sociedade e universidade. Educação \& Sociedade, v. 19, n. 63, p. 53-79. 1998.

HERNÁNDEZ, M. O. A educação de habilidades sociais a partir da Extensão universitária: Proposta de ações. Educar em Revista. n. 50, p. 269-283. 2013.

KAWASAKI, C. S. Universidades Públicas e Sociedade: uma parceria necessária. Revista da Faculdade de Educação, São Paulo, v. 23, n.1-2, 1997.

LEITE, F. C. L.; COSTA, S. M. S. Gestão do conhecimento científico. Ciência da Informação. Brasília, v. 36, n. 1, p. 92-107, 2007. 
LEYDESDORFF, L. Scientific communication and cognitive codification: social systems and sociology of scientific knowledge. European Journal of Social Theory, v.10, n.3,p.1-22, 2007.

MORAES, R. C. C. Universidade hoje - Ensino, pesquisa, extensão. Educação \& Sociedade, v. 19, n. 63, p. 19-37, 1998.

RECOTILLET, I. PhD graduates with Post-Doctoral qualification in the private sector. Labour, v. 21, n. 3, p. 473-502, 2007.

SOUZA-SILVA, J. C.; DAVEL, E. Concepções, práticas e desafios na formação do professor: Examinando o caso do ensino superior de administração no Brasil. Organizações \& Sociedade, v. 12, n. 35, p. 113-134, 2005.

VALADÃO JR., V. M.; RODRIGUES, H. G. Competências na pós-graduação: O olhar dos egressos. Administração: Ensino e pesquisa, v. 13, n. 2, p. 325-354, 2012. 


\section{ANEXO I - PARTICIPANTES DA PESQUISA}

Distribuição dos pesquisadores com pós-doutorado e suas respectivas áreas.

\begin{tabular}{|c|c|c|c|c|c|}
\hline Área & Número & Percentual & Área & Número & Percentual \\
\hline Biologia Geral & 2 & $0,2 \%$ & Engenharia Aeroespacial & 4 & $0,41 \%$ \\
\hline Biofísica & 2 & $0,2 \%$ & Engenharia Biomédica & 6 & $0,61 \%$ \\
\hline Bioquímica & 13 & $1,33 \%$ & Engenharia Civil & 18 & $1,84 \%$ \\
\hline Botânica & 3 & $0,31 \%$ & Engenharia de Materiais & 7 & $0,72 \%$ \\
\hline Ecologia & 10 & $1,02 \%$ & Engenharia de Minas & 1 & $0,1 \%$ \\
\hline Farmacologia & 7 & $0,72 \%$ & Engenharia de Produção & 6 & $0,61 \%$ \\
\hline Fisiologia & 17 & $1,74 \%$ & Engenharia de & & \\
\hline Genética e Melhoramento & 11 & $1,12 \%$ & Transportes & 3 & $0,31 \%$ \\
\hline Imunologia & 7 & $0,72 \%$ & Engenharia Elétrica & 24 & $2,45 \%$ \\
\hline Microbiologia & 11 & $1,12 \%$ & Engenharia Mecânica & 23 & $2,35 \%$ \\
\hline Morfologia & 5 & $0,51 \%$ & Engenharia Oceânica & 1 & $0,1 \%$ \\
\hline Parasitologia & 5 & $0,51 \%$ & Engenharia Química & 10 & $1,02 \%$ \\
\hline Zoologia & 8 & $0,82 \%$ & Engenharia Sanitária & 9 & $0,92 \%$ \\
\hline Biológicas & 101 & $10,3 \%$ & Engenharias & 112 & $11,5 \%$ \\
\hline Administração & 22 & $2,25 \%$ & & & \\
\hline Arquitetura e Urbanismo & 13 & $1,33 \%$ & Educação Física & 10 & $1,02 \%$ \\
\hline Ciência da Informação & 4 & $0,41 \%$ & Enfermagem & 13 & $1,33 \%$ \\
\hline Comunicação & 19 & $1,94 \%$ & Farmácia & 12 & $1,23 \%$ \\
\hline Demografia & 4 & $0,41 \%$ & Fisioterapia & 2 & $0,2 \%$ \\
\hline Desenho Industrial & 3 & $0,31 \%$ & Fonoaudiologia & 2 & $0,2 \%$ \\
\hline Direito & 18 & $1,84 \%$ & Medicina & 50 & $5,11 \%$ \\
\hline Economia & 20 & $2,04 \%$ & Nutrição & 3 & $0,31 \%$ \\
\hline Museologia & 1 & $0,1 \%$ & Odontologia & 22 & $2,25 \%$ \\
\hline Serviço Social & 6 & $0,61 \%$ & Terapia Ocupacional & 2 & $0,2 \%$ \\
\hline Planej. Urbano e Regional & 6 & $0,61 \%$ & Saúde Coletiva & 19 & $1,94 \%$ \\
\hline
\end{tabular}




\begin{tabular}{|c|c|c|c|c|c|}
\hline Área & Número & Percentual & Área & Número & Percentual \\
\hline Sociais Aplicadas & 116 & $11,9 \%$ & Saúde & 135 & $13,8 \%$ \\
\hline Antropologia & 20 & $2,04 \%$ & & & \\
\hline Ciência Política & 7 & $0,72 \%$ & Astronomia & 6 & $0,61 \%$ \\
\hline Educação & 41 & $4,19 \%$ & Computação & 29 & $2,97 \%$ \\
\hline Filosofia & 32 & $3,27 \%$ & Estatística & 3 & $0,31 \%$ \\
\hline Geografia & 10 & $1,02 \%$ & Física & 33 & $3,37 \%$ \\
\hline História & 35 & $3,58 \%$ & Química & 37 & $3,78 \%$ \\
\hline Psicologia & 24 & $2,45 \%$ & Geociências & 21 & $2,15 \%$ \\
\hline Sociologia & 29 & $2,97 \%$ & Matemática & 26 & $2,66 \%$ \\
\hline Teologia & 1 & $0,1 \%$ & Oceanografia & 5 & $0,51 \%$ \\
\hline Humanas & 199 & $20,3 \%$ & Exatas e da Terra & 160 & $16,4 \%$ \\
\hline Agronomia & 28 & $2,86 \%$ & Artes & 14 & $1,43 \%$ \\
\hline Engenharia Agrícola & 2 & $0,2 \%$ & Letras & 35 & $3,58 \%$ \\
\hline Engenharia Florestal & 5 & $0,51 \%$ & Linguística & 17 & $1,74 \%$ \\
\hline Medicina Veterinária & 8 & $0,82 \%$ & Letras, Linguística e Artes & 66 & $6,7 \%$ \\
\hline Tecnologia de Alimentos & 7 & $0,72 \%$ & & & \\
\hline Zootecnia & 15 & $1,53 \%$ & & & \\
\hline Agrárias & 65 & $6,6 \%$ & Multidisciplinar & 24 & $2,5 \%$ \\
\hline$\overline{\text { Total }}$ & 978 & $100,0 \%$ & & & \\
\hline
\end{tabular}




\section{ANEXO II - ITENS DE REAÇÃO DOS COLEGAS}

O mencionado na Figura 7 deriva de dois itens do questionário, respondido pelos docentes:

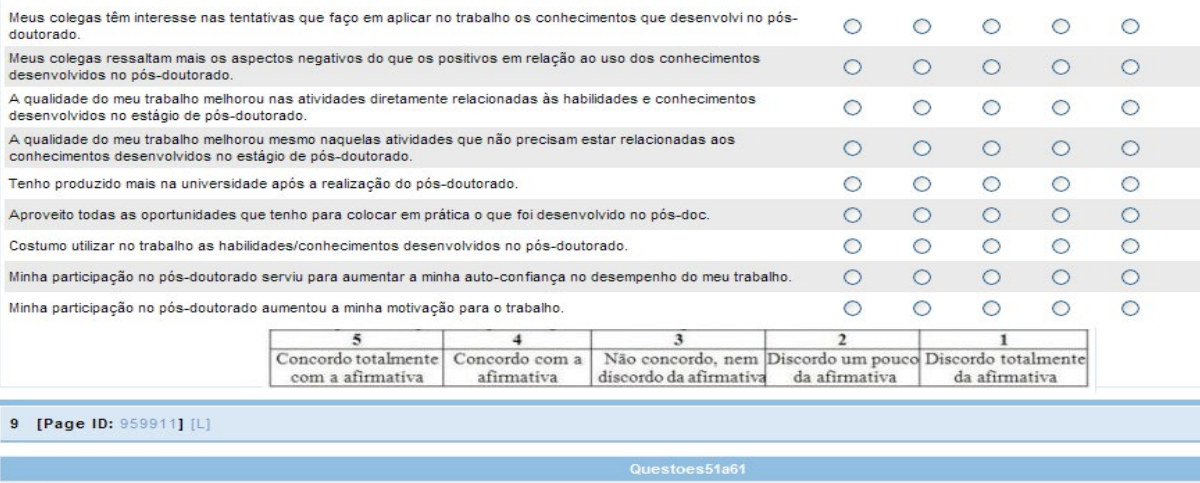

Onde a escala significava:

\begin{tabular}{|c|c|c|c|c|c|c|c|}
\hline \multicolumn{3}{|c|}{$\begin{array}{l}\text { Meus colegas têm interesse nas tentativas que faço em aplicar no trabalho os conhecimentos que desenvolvi no pós- } \\
\text { doutorado. }\end{array}$} & pós- & O & 0 & 0 & 0 \\
\hline \multicolumn{3}{|c|}{$\begin{array}{l}\text { Meus colegas ressaltam mais os aspectos negativos do que os positivos em relação ao uso dos conhecimentos } \\
\text { desenvolvidos no pós-doutorado. }\end{array}$} & 0 & 0 & 0 & 0 & 0 \\
\hline \multicolumn{3}{|c|}{$\begin{array}{l}\text { A qualidade do meu trabalho melhorou nas atividades diretamente relacionadas às habilidades e conhecimentos } \\
\text { desenvolvidos no estágio de pós-doutorado. }\end{array}$} & 0 & O & 0 & 0 & O \\
\hline \multicolumn{3}{|c|}{$\begin{array}{l}\text { A qualidade do meu trabalho melhorou mesmo naquelas atividades que não precisam estar relacionadas aos } \\
\text { conhecimentos desenvolvidos no estágio de pós-doutorado. }\end{array}$} & O & 0 & 0 & 0 & 0 \\
\hline \multicolumn{3}{|c|}{ Tenho produzido mais na universidade após a realização do pós-doutorado. } & 0 & 0 & 0 & 0 & 0 \\
\hline \multicolumn{3}{|c|}{ Aproveito todas as oportunidades que tenho para colocar em prática o que foi desenvolvido no pós-doc. } & 0 & 0 & 0 & 0 & 0 \\
\hline \multicolumn{4}{|c|}{ Costumo utilizar no trabalho as habilidades/conhecimentos desenvolvidos no pós-doutorado. } & 0 & 0 & 0 & 0 \\
\hline \multicolumn{4}{|c|}{ Minha participação no pós-doutorado serviu para aumentar a minha auto-confiança no desempenho do meu trabalho. } & 0 & 0 & 0 & 0 \\
\hline \multicolumn{3}{|c|}{ Minha participação no pós-doutorado aumentou a minha motivação para o trabalho. } & 0 & 0 & 0 & 0 & \multirow[t]{3}{*}{ O } \\
\hline 5 & 4 & 3 & 2 & & 1 & & \\
\hline $\begin{array}{l}\text { Concordo totalmente } \\
\text { com a afirmativa }\end{array}$ & $\begin{array}{c}\text { Concordo com a } \\
\text { afirmativa }\end{array}$ & $\begin{array}{l}\text { Nâo concordo, nem } \\
\text { discordo da afirmativa }\end{array}$ & $\begin{array}{l}\text { Discordo um pouc } \\
\text { da afirmativa }\end{array}$ & \multicolumn{3}{|c|}{$\begin{array}{c}\text { Discordo totalmente } \\
\text { da afirmativa }\end{array}$} & \\
\hline 9 [Page ID: 959911] [L] & & & & & & & \\
\hline
\end{tabular}

Com a escala invertida para a segunda assertiva, considerou-se para efeitos da pesquisa r e 2 como reação "desfavorável" dos colegas; 3 reação "neutra"; e, 4 e 5 como avaliação de uma reação "favorável" por parte dos colegas. 


\section{NOTAS DE FIM}

I: A variação média é obtida pelo somatório do cálculo (pontos/ano depois)/ (pontos/ano antes) de cada docente divido por $n$ e, por isso, o resultado de variação apresentada não é uma relação exata das duas colunas, que a representam. 


\section{DADOS DOS AUTORES}

\section{PEDRO MARCOS ROMA DE CASTRO^ pedro.castro@capes.gov.br} Doutor em Administração pela USP

Instituição de vinculação: Coordenação de Aperfeiçoamento de Pessoal de Nível Superior

Brasília/DF - Brasil

Áreas de interesse em pesquisa: Ensino e Pesquisa, Treinamento e Desenvolvimento, Educação Corporativa e Pós-graduação brasileira.

^ SBN Quadra 2, Bloco L, Lote 06, $8^{\circ}$ andar, Universidade Aberta do Brasil (UAB)

Capes-Brasília, DF 70.040-020

\section{GECIANE SILVEIRA PORTO geciane@usp.br}

\section{Livre Docente em Administração pela USP}

Instituição de vinculação: Universidade de São Paulo - Campus Ribeirão Preto Ribeirão Preto/SP - Brasil

Áreas de interesse em pesquisa: Indicadores de Ciência, Tecnologia e Inovação, Gestão Tecnológica, Gestão Universitária, Educação a Distância, Ensino e Pesquisa em Administração. 